\title{
The possibilities of application of radiant wall cooling in existing buildings as a part of their retrofit
}

\author{
Michal Krajčík ${ }^{1, *}$ and Ondřej Šikula ${ }^{2}$ \\ ${ }^{1}$ Slovak University of Technology, Faculty of Civil Engineering, Radlinského 11, 81005 Bratislava, Slovakia \\ ${ }^{2}$ Brno University of Technology, Faculty of Civil Engineering, Veveř́ 331/95, 60200 Brno, Czech Republic
}

\begin{abstract}
In the following years and decades the increase in cooling capacity will put tremendous pressure on the energy infrastructure and severely increase the environmental impacts. In a moderate climate and well thermally insulated buildings like, e.g., in Europe, installation of low-exergy radiant systems could help alleviate these negative effects. Wall systems may be especially suitable for installation in existing buildings, however, their possible applications in buildings retrofit have not been fully explored. We therefore investigate the possible applications of wall cooling in existing buildings by numerical simulations of twodimension heat flow through a wall fragment. Three wall systems are proposed and compared in terms of thermal response and heat transfer. The effect of various parameters is investigated to facilitate the design of the wall systems.
\end{abstract}

\section{Introduction}

It is expected that in the following years and decades the increase in cooling capacity and number of space cooling systems will put tremendous pressure on the energy infrastructure and severely increase the environmental impacts if the design of cooling systems is not optimized $[1,2]$. Installation of low-exergy water-based radiant systems could help alleviate these negative effects due to their suitability for combination with low-grade renewable energy sources such as ground-coupled heat pumps and solar collectors $[3,4]$, the high sensible cooling capacity [5], and the possibility to use the same system both for heating and cooling. In a moderate and dry climate and well thermally insulated building like, e.g., in Europe, only a fragment of surface may be sufficient to create thermal comfort throughout the whole year [6]. This makes radiant walls potentially feasible systems for buildings retrofit, which could be preferable to the more common radiant floors or ceilings due to their benefits as follows:

- Suitability for retrofitted buildings. Additional installation of a radiant wall system does not reduce the net story height. In contrast, additional installation of floor or ceiling system adds to the thickness of the floor or ceiling structure and diminish the precious net height, possibly beyond the acceptable limit.

- Comfortable thermal environment. Compared to radiant floors, wall cooling creates a more homogeneous thermal environment and reduces the risk of thermal discomfort due to cold floors in spaces like residential rooms and cellular offices $[7,8]$.
- Higher heating and cooling capacity. The cooling capacity is higher for radiant walls $\left(70 \mathrm{~W} / \mathrm{m}^{2}\right)$ than for radiant floors $\left(40 \mathrm{~W} / \mathrm{m}^{2}\right)$ because of the higher convection heat transfer coefficient [9], though lower than for chilled ceilings $\left(100 \mathrm{~W} / \mathrm{m}^{2}\right)$. However, the same system can be used for heating, with the maximum capacity of $160 \mathrm{~W} / \mathrm{m}^{2}$, superior to that of radiant floors $\left(100 \mathrm{~W} / \mathrm{m}^{2}\right)$ and radiant ceilings $\left(40 \mathrm{~W} / \mathrm{m}^{2}\right)[5]$.

- Possibility of operation as a thermal barrier to reduce heat transmission through the walls. This is possible in situations when the water temperature is very close to the room temperature, thus preventing heat losses in winter $[10,11]$ and absorbing external heat gains in summer [12].

The contemporary research focuses on radiant floors and ceilings. Much less attention is paid to radiant walls despite their potential benefits. The specifics of radiant walls have not been fully considered. Moreover, the focus is on new buildings, and the research regarding the application of radiant wall systems in existing buildings as a part of their retrofit is lacking. This study therefore aims to explore the potential applications of wall cooling in retrofitted buildings by dynamic and stationary numerical simulations of heat transfer through a fragment of wall. The contributions are summarized as follows:

- We propose three types of wall cooling systems, differing by their construction and thermal response. These systems are potentially suitable for installation in existing buildings as a part of their retrofit, which could facilitate the use of renewable energy sources such as heat pumps and solar collectors.

\footnotetext{
* Corresponding author: michal.krajcik@stuba.sk
} 
- Systems "a" and "b" in Fig. 1 represent TABS with variable location of pipes. System "c" represents an alternative with pipes embedded in plaster, thermally insulated from the main structure. We compare these systems in terms of thermal response and heat transfer.

- To facilitate the design of wall cooling systems, we study the effect of various parameters such as thermal conductivity of the bearing structure, thickness of the bearing structure and thermal insulation, spacing of pipes, and location on external vs. on internal wall.

\section{Wall cooling systems investigated}

The three types of radiant wall systems investigated are shown in Fig. 1. Each wall system was studied for two materials of the bearing structure, porous and reinforced concrete. The porous concrete was chosen as a representative of materials with low thermal conductivity, such as porous ceramic bricks and ceramic hollow bricks. Reinforced concrete with high thermal conductivity was considered as an alternative because of its frequent use in building construction. This makes the results applicable for a wide range of existing buildings. The wall cooling systems can be characterized as follows:

- System "a" has pipes embedded in a plaster between bearing structure and thermal insulation. This system can be attached to the facades of existing buildings without any significant interventions on the interior side.

- System "b" has pipes embedded underneath the surface in a plaster. The pipes are thermally coupled to the bearing structure.

- System "c" corresponds to the system "b", but in this case the pipes are thermally decoupled from the bearing structure by a layer of thermal insulation.

It should be noted that a) systems "a" and "b" are thermally coupled to the bearing structure and thus represent thermally active building systems (TABS), and b) all systems can be installed both on external and on internal walls.

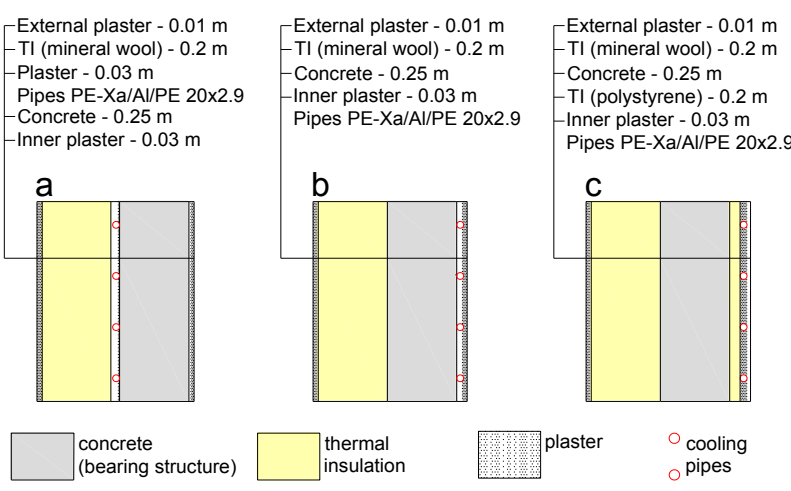

Fig. 1. Radiant wall cooling systems investigated.

\section{Physical model, calculation method}

The results were obtained by solving a set of equations of two-dimensional heat transfer by conduction, using a dedicated CalA software [13,14], which has been validated in accordance with [15]. The heat flux and temperature distribution were calculated for a horizontally symmetrical fragment of a radiant wall (Fig. 2). Stationary simulations were used for parametric studies. Dynamic simulations were performed to study the thermal dynamics of the wall cooling systems.

\subsection{Thermo-physical properties of the wall}

The thickness and thermo-physical properties of the material layers in Fig. 1 are described in Tab 1. The Uvalue of all types of wall is equal to or less than 0.15 $\mathrm{W} /\left(\mathrm{m}^{2} . \mathrm{K}\right)$. This corresponds to a wall of a nearly zero energy building in the region of Central Europe.

Table 1. Thermo-physical properties of the material layers.

\begin{tabular}{|l|l|c|c|c|c|}
\hline No. & Material & Thickness & $\begin{array}{c}\text { Vol. } \\
\text { weight } \\
\mathrm{m}\end{array}$ & $\begin{array}{c}\text { Thermal } \\
\text { conductivity } \\
\mathrm{W} /(\mathrm{m} . \mathrm{K})\end{array}$ & $\begin{array}{c}\text { Specific } \\
\text { heat } \\
\text { capacity } \\
\mathrm{J} /(\mathrm{kg} . \mathrm{K})\end{array}$ \\
\hline$(1)$ & Inner plaster & $0.01-0.03$ & 1300 & 0.7 & 840 \\
\hline$(2)$ & $\begin{array}{l}\text { Insulation - EPS F } \\
\text { (only in system "c") }\end{array}$ & 0.03 & 17 & 0.04 & 1020 \\
\hline$(3)$ & $\begin{array}{l}\text { Porous concrete or } \\
\text { reinforced concrete }\end{array}$ & 0.2 & 600 & 0.19 & 1000 \\
\hline$(4)$ & $\begin{array}{l}\text { Plaster containing } \\
\text { the pipes } \\
\text { (only in system “ } a \text { ") }\end{array}$ & 0.03 & 1300 & 0.7 & 840 \\
\hline (5) & $\begin{array}{l}\text { Insulation - mineral } \\
\text { wool }\end{array}$ & 0.2 & 20 & 0.04 & 940 \\
\hline (6) & Outer plaster & 0.01 & 1600 & 0.8 & 840 \\
\hline (7) & Plastic pipe DN 20 & & 1200 & 0.35 & 1000 \\
\hline
\end{tabular}

\subsection{Principle of calculation}

The calculation was based on a detailed numerical solution of two-dimension stationary temperature field by the method of rectangle-shaped control volumes, each representing a single temperature [16]. The distribution of the temperature in the Cartesian coordinate system was described by the Fourier equation of thermal diffusion [17]:

$$
\frac{\partial}{\partial x}\left(\lambda \frac{\partial T}{\partial x}\right)+\frac{\partial}{\partial y}\left(\lambda \frac{\partial T}{\partial y}\right)+S=\rho \cdot c \cdot \frac{\partial T}{\partial \tau}
$$

where $T$ is the temperature (K); $S$ is an internal heat source $\left(\mathrm{W} / \mathrm{m}^{3}\right) ; \tau$ is time $(\mathrm{s}) ; \lambda$ is thermal conductivity $(\mathrm{W} /(\mathrm{m} . \mathrm{K}))$; $\rho$ is bulk density $\left(\mathrm{kg} / \mathrm{m}^{3}\right)$; and $c$ is the specific heat capacity at a constant pressure $(\mathrm{J} /(\mathrm{kg} . \mathrm{K}))$.

The heat transfer coefficient for the water and pipe surface $\alpha$ was determined to be $1218 \mathrm{~W} /\left(\mathrm{m}^{2} . \mathrm{K}\right)$. The boundary conditions defining the specific heat flux on the surface of a computational domain were calculated according to the Newton's law of cooling, assuming adiabatic boundaries of the wall fragment (Fig. 2). The temperature and heat flux distribution over time was calculated using the Robin-Newton's boundary condition.

The simulated fragment represented a section of radiant wall, symmetrical along the horizontal axis. The pipes in the radiant wall were spaced regularly and the 
temperature of the water in the pipes and material properties were considered homogeneous along the wall.

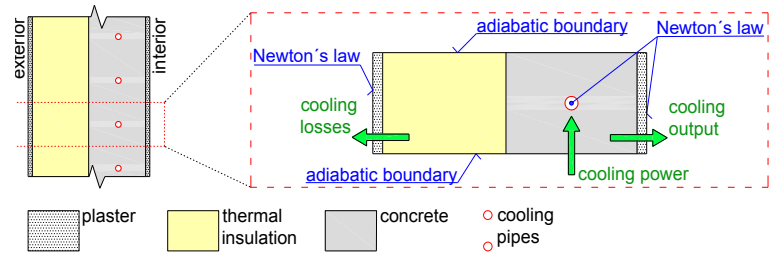

Fig. 2. Boundary conditions defining specific heat flux on a wall surface.

\subsection{Boundary conditions}

The room temperature of $26^{\circ} \mathrm{C}$ used in the simulations is interpreted as the operative temperature [18]. The mean temperature of cooling water was $20^{\circ} \mathrm{C}$, considered as typical for radiant cooling systems operated under design weather conditions in temperate climates. In stationary simulations the combined effect of ambient temperature and solar radiation incident on the wall was approximated by the sol-air temperature $\left(T_{\text {sol-air }}\right)[17]$ :

$$
T_{\text {sol-air }}=T_{a m b}+\frac{\alpha \cdot I_{g}}{h_{e}}-\frac{\varepsilon \cdot \Delta R}{h_{e}}
$$

where $T_{\mathrm{amb}}$ is the temperature of the ambient air $\left({ }^{\circ} \mathrm{C}\right), \alpha$ is the absorptance of surface for solar radiation $(-), I_{\mathrm{g}}$ is the solar radiation incident on the wall $\left(\mathrm{W} / \mathrm{m}^{2}\right), h_{\mathrm{e}}$ is the coefficient of heat transfer by long-wave radiation and convection at outer surface $\left(\mathrm{W} /\left(\mathrm{m}^{2} \cdot \mathrm{K}\right)\right)$. The correction term for the vertical surfaces $\varepsilon . \Delta R$ is $0{ }^{\circ} \mathrm{C}$ under the assumption that the long-wave radiation emitted by the warm surfaces of terrestrial objects at high solar radiation compensates to some extent for the sky's low emittance [19]. The absorptance of the external wall surface is assumed 0.5 , typical of, e.g., sandstone paint [20].

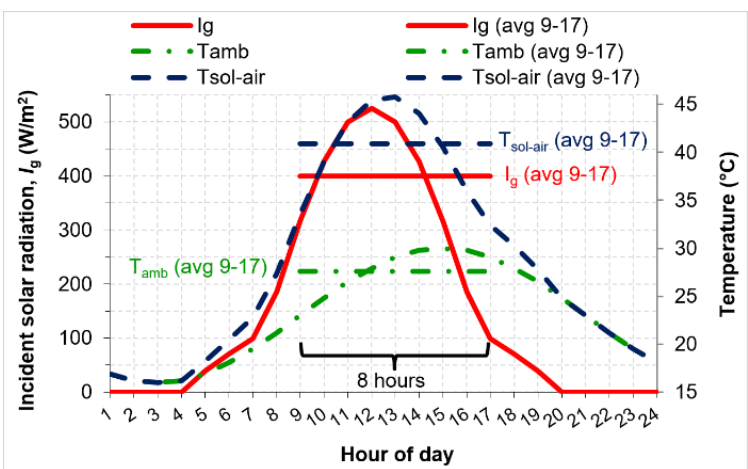

Fig. 3. The course of ambient temperature, sol-air temperature and incident radiation on a southern wall in July, and the average values used in stationary simulations.

The course of sol-air temperature for the investigated month of July and a southern wall is shown in Fig. 3 together with the input data. These values represent design conditions that can be considered typical for the region of Central Europe [21]. To account for the dampening effect of thermal inertia on the heat transfer through the wall, the inputs were averaged over eight hours. The sol-air temperature $\left(T_{\text {sol-air }}\right)$ averaged over the eight-hour period and used in the stationary simulations was $41^{\circ} \mathrm{C}$. In the dynamic calculations the sol-air temperature was not used. The solar radiation was simulated by an external heat source instead.

The heat transfer coefficient on the inner surface of the wall was $8 \mathrm{~W} /\left(\mathrm{m}^{2} . \mathrm{K}\right)$ as defined in EN ISO 11855-2 [22]. It was kept constant throughout the simulations to avoid bias by factors that were not the subject of our investigations. The heat transfer coefficient on the outer side of the wall was $15 \mathrm{~W} /\left(\mathrm{m}^{2} . \mathrm{K}\right)$ as defined in [23].

\section{Parameters investigated}

The parameters investigated are shown in Tab. 2. All systems were characterized in terms of their: (1) thermal response to analyse their thermal dynamics; (2) cooling output and losses; (3) potential of reduction of cooling losses by location on internal instead of external wall; (4, 5 ) sensitivity to the thickness of thermal insulation and bearing structure and to the spacing of pipes; (6) sensitivity to thermo-physical properties of the material of the bearing structure.

Table 2. Parameters investigated.

\begin{tabular}{|l|c|c|c|c|c|c|}
\hline System & $\begin{array}{c}\text { Thermal } \\
\text { response } \\
(\mathrm{h})\end{array}$ & $\begin{array}{c}\text { Heat } \\
\text { flux } \\
\left(\mathrm{W} / \mathrm{m}^{2}\right)\end{array}$ & $\begin{array}{c}\text { Wall } \\
\text { location }\end{array}$ & $\begin{array}{c}\text { Thickness } \\
\text { of wall } \\
(\mathrm{mm})\end{array}$ & $\begin{array}{c}\text { Spacing } \\
\text { of pipes } \\
(\mathrm{mm})\end{array}$ & $\begin{array}{c}\text { Wall } \\
\text { material }\end{array}$ \\
\hline a & Dyn. & Stat. & Stat. & Stat. & Stat. & Stat. \\
\hline b & Dyn. & Stat. & Stat. & Stat. & Stat. & Stat. \\
\hline \hline c & Dyn. & Stat. & Stat. & Stat. & Stat. & Stat. \\
\hline
\end{tabular}

Key: Dyn. - dynamic simulations, Stat. - stationary simulations

\section{Results and discussion}

\subsection{Thermal response}

We computed thermal response to characterize thermal dynamics of the wall cooling systems. The thermal response was defined as $\tau_{95}$, i.e. "the time it takes for the surface temperature of a radiant system to reach $95 \%$ of the difference between its final and initial values when a step change in control of the system is applied as input" [24]. In this study the step change is represented by changing the initial temperature of water in the pipes, equal to the operative temperature on both sides of the wall, from $26^{\circ} \mathrm{C}$ to $20^{\circ} \mathrm{C}$.

Although the thermal response $\tau_{95}$ is a valid indicator of thermal dynamics of radiant systems, Figs. 4 and 5 illustrate the limitations of this indicator when attempting to compare the wall cooling systems. In Fig. 4 the thermal response of wall system "a" is shown for the two materials of the bearing structure, porous and reinforced concrete. The thermal response is almost identical in both cases, however, the surface temperature of the inner wall at $\tau_{95}$ differs considerably. This difference in thermal dynamics between the two materials of the bearing structure is not obvious from the thermal response. 


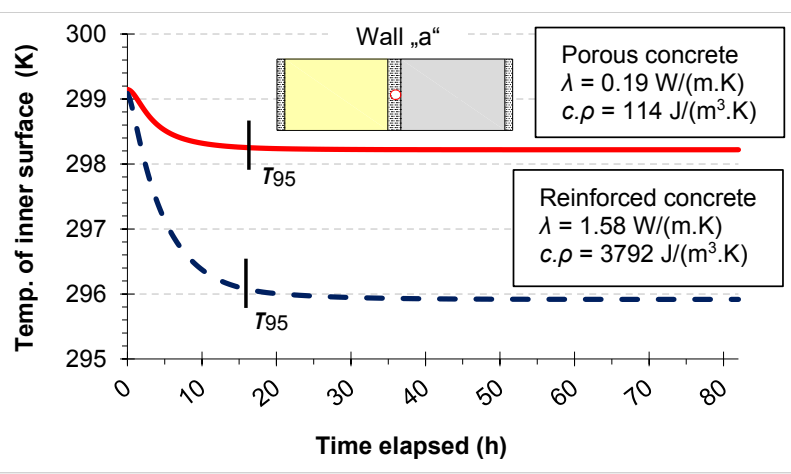

Fig. 4. Thermal response $\tau_{95}$ for wall cooling system "b" with bearing structure made of porous or reinforced concrete. Thickness of concrete $200 \mathrm{~mm}$, thickness of insulation 200 $\mathrm{mm}$, spacing of pipes $150 \mathrm{~mm}$.

Fig. 5 compares the thermal response of wall cooling systems "b" and "c", both with the bearing structure made of reinforced concrete. In this case the thermal response of both systems is similar, and it does not reflect the differences in thermal dynamics of the wall systems. The thermal response $\tau_{95}$ is 27.5 hours for wall "c" despite the fast change in the surface temperature of the inner wall after the step change. This means that thermal response $\tau_{95}$ does not reflect the fast reaction of the wall system caused by the low cool storage capacity of the active layer.

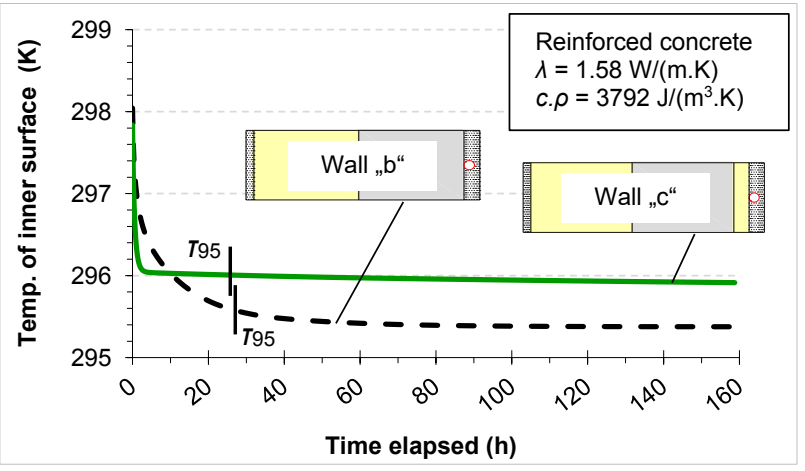

Fig. 5. Thermal response $\tau_{95}$ for wall cooling systems "b" and "c" with bearing structure made of reinforced concrete. Thickness of concrete $200 \mathrm{~mm}$, thickness of insulation 200 $\mathrm{mm}$, spacing of pipes $150 \mathrm{~mm}$.

These limitations should be taken into consideration when comparing the wall systems in terms of their thermal response as shown in Fig. 6. The bars represent the range of thermal response obtained for the various types of wall systems, and for the two materials of the bearing structure. Each range represents nine combinations of the thickness of concrete $(200,300$, and $400 \mathrm{~mm})$ and the spacing of pipes $(150,200$, and $250 \mathrm{~mm})$.

For wall system " $b$ " the range of thermal response is wider when the bearing structure is made of reinforced concrete as compared to the porous concrete. This is because the specific cool capacity is much higher for reinforced concrete. Consequently, the bearing structure accumulates more cool and it takes longer for the surface temperature to reach $95 \%$ of its final value.

On the other hand, the results are completely opposite for thermal response of wall system "a". In this case locating the pipes between the bearing structure and thermal insulation resulted in a much wider range of thermal response when the bearing structure was made of porous concrete.

The results of thermal response for wall system "c" may not reflect the true thermal dynamics of the system, especially in the case of reinforced concrete (Fig. 5). Due to its fast response to a step change, the thermal response of this system is extremely sensitive to its definition. For example, the thermal response of wall system "c" is similar to the thermal response of wall systems "a" and "b" when defined as $\tau_{95}$ (Fig. 6), but it is considerably lower than for the wall systems "a" and " $b$ " when defined as $\tau_{63}$.

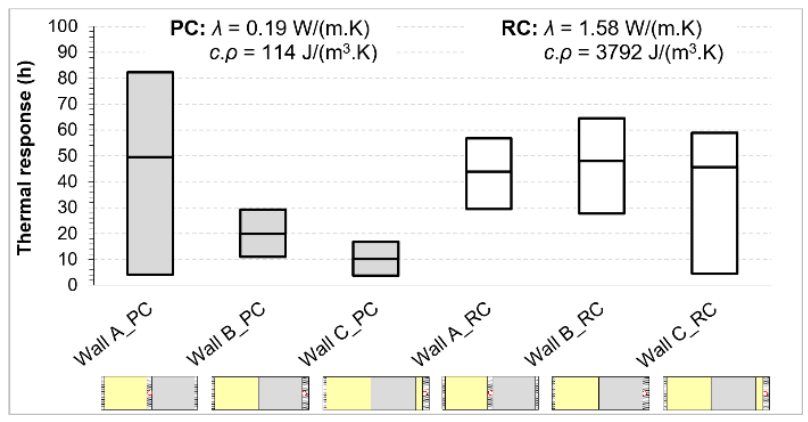

Fig. 6. Thermal response of the three types of wall systems for two materials of bearing structure - porous concrete (PC) and reinforced concrete (RC).

\subsection{Heat transfer for various pipe arrangements}

The cooling output may vary considerably depending on the wall system used and on the material of the bearing structure (Fig. 7). The results refer to wall cooling systems located on external walls, i.e. exposed to weather conditions. From all the wall systems investigated, system "a" has the lowest cooling capacity, is the most sensitive on the material of the bearing structure used, and its ratio of cooling loses to total cooling power supplied to the wall through the pipes (L) is the highest. The cooling output is greatest for wall system " $b$ " combined with the thermally conductive reinforced concrete as the bearing structure.

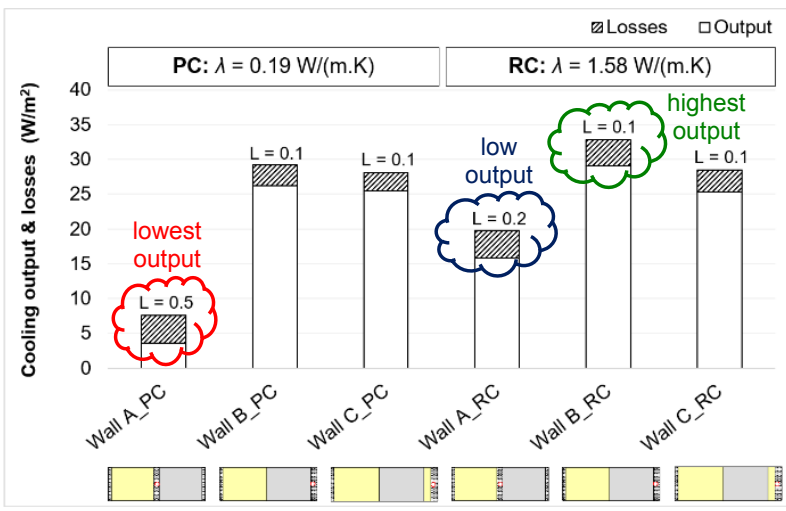

Fig. 7. Cooling output and losses for various pipe arrangements. Wall system located on external wall. Key: L ratio of cooling loses to the cooling power supplied to the wall, $\mathrm{PC}$ - porous concrete, RC - reinforced concrete. 
The results in Fig. 7 can be better understood by looking at the visualisation of the thermal field and cooling output in Fig. 8. In The visualisations refer to wall systems with the bearing structure made of porous concrete. Wall system " $a$ " has the lowest cooling output. The cool is well distributed within the plaster, which, however, is insulated by thermal insulation on one side and by the porous concrete with low thermal conductivity on the other side. The cooling output improves when the bearing structure is made of thermally conductive reinforced concrete, yet it is still inferior that for wall systems " $b$ " and "c" (Fig. 7).

The cooling output and losses are slightly higher for wall system "b" as compared to the wall system " $c$ ". This difference is attributed to the insulation between the cooling pipes and the bearing structure in the wall system "c", which reduces the cooling losses. On the other hand, the low thickness of the thermally active inner plaster in wall system "c" prevents a more homogeneous distribution of cool at the inner surface, and thereby reduces the cooling output.

\begin{tabular}{|c|c|c|c|}
\hline & Physical model & Thermal field & Cooling output \\
\hline $\mathrm{a}$ & & E $\begin{array}{l}\text { Lowest } \\
\text { output }\end{array}$ & $1 . \begin{array}{c}\text { cool } \\
\text { distributed } \\
\text { in plaster }\end{array}$ \\
\hline$b$ & & $\begin{array}{l}\text { Higher output } \\
\text { than "c" }\end{array}$ & $\begin{array}{l}\text { Higher losses } \\
\text { than "c" }\end{array}$ \\
\hline $\mathrm{c}$ & & $\begin{array}{l}\text { Lower output } \\
\text { than "b" }\end{array}$ & $\begin{array}{l}\text { Lower losses } \\
\text { than "b" }\end{array}$ \\
\hline
\end{tabular}

Fig. 8. Visualisation of thermal field and cooling output. Bearing structure made of porous concrete, $\lambda=0.19 \mathrm{~W} /(\mathrm{m} . \mathrm{K})$.

\subsection{Location on internal wall}

The cooling losses depend significantly on type of system, material of the bearing structure, and room temperature on the other side of the wall when the cooling system is located on an internal wall (Fig. 9). This observation refers to the case with no thermal insulation. Regardless of the case investigated, the cooling losses are always highest and the cooling output is always lowest for wall system "a". This system should be therefore used only in special cases when installation on the inner side of the wall is not appropriate.

For the wall systems " $b$ " and "c" the cooling losses are lower when combined with porous concrete as compared to the thermally conductive reinforced concrete. This is because of the ability of porous concrete to better insulate the pipes from the environment on the other side of the wall.

The losses are lowest for the wall system "c" with the pipes thermally insulated from the bearing structure. Especially when the bearing structure is made of the thermally conductive reinforced concrete, wall system "c" is preferable to the other systems because of its low cooling losses.

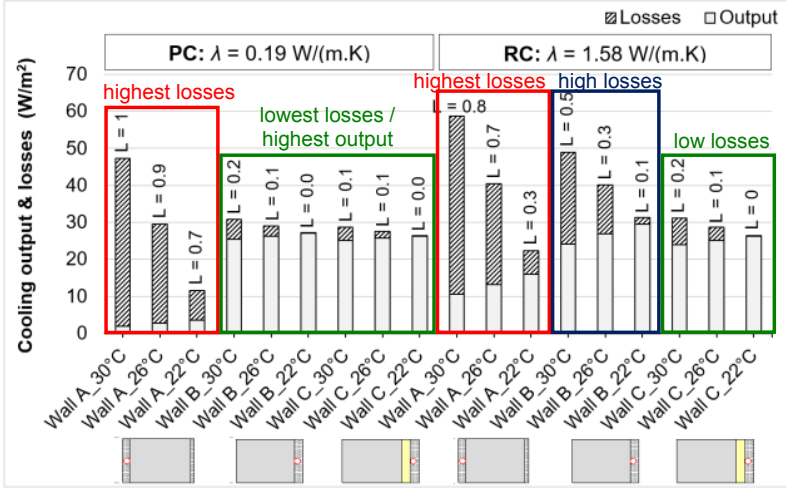

Fig. 9. Cooling output and losses for various pipe arrangements. Wall system located on internal wall. Key: L ratio of cooling loses to the cooling power supplied to the wall, $\mathrm{PC}$ - porous concrete, $\mathrm{RC}$ - reinforced concrete.

\subsection{Thickness of the wall, spacing of the pipes}

Fig. 10 shows the effect of thickness of thermal insulation on the cooling output. For wall system "a" with the bearing structure made of porous concrete the cooling output remains very low, regardless of the thickness of insulation (Fig. 10a). On the other hand, the cooling output of wall systems " $b$ " and "c" is almost identical, and it changes only slightly with increasing thickness of thermal insulation. Here the low thermal conductivity of porous concrete has a positive effect, and reduces the cooling losses.

The thickness of thermal insulation becomes more important when the bearing structure is made of the thermally conductive reinforced concrete (Fig. 10b). For the thermally active wall systems "a" and "b", the first 50 $\mathrm{mm}$ of insulation is crucial. Beyond this thickness, adding more insulation affects the cooling output only to a small extent. The effect of thermal insulation is less important for wall system "c" because of the insulation layer between the plaster containing pipes and the concrete core. For the thickness of the concrete of $300 \mathrm{~mm}$ and 400 $\mathrm{mm}$ the results were similar regardless of the thickness of the bearing structure.

Spacing of pipes has an important effect on the cooling output of wall systems " $b$ " and "c" regardless of the material of the bearing structure (Fig. 11). The effect is smaller wall system "a", and it is more pronounced when the bearing structure is made of the thermally conductive reinforced concreted as compared to the porous concrete.

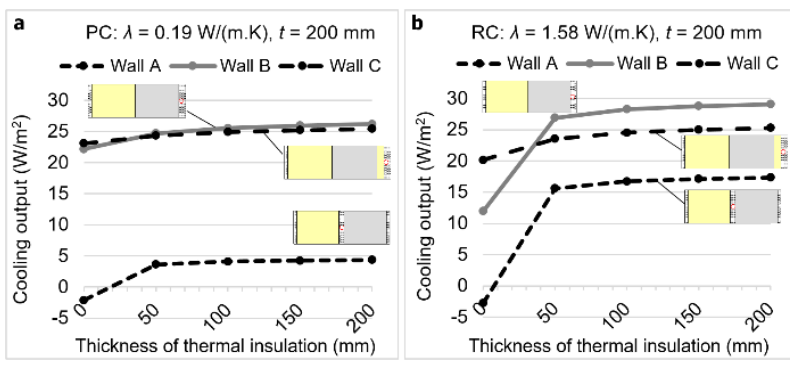

Fig. 10. The effect of thickness of thermal insulation on the cooling output: a) porous concrete, PC: $\lambda=0.19 \mathrm{~W} /(\mathrm{m} . \mathrm{K}), \mathrm{b})$ reinforced concrete, RC: $\lambda=1.58 \mathrm{~W} /(\mathrm{m} . \mathrm{K})$. Thickness of concrete $t=200 \mathrm{~mm}$. 


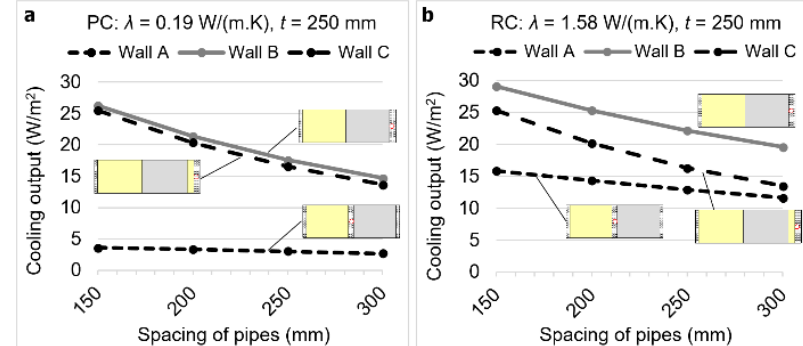

Fig. 11. The effect of spacing of pipes on the cooling output: a) porous concrete, PC: $\lambda=0.19 \mathrm{~W} /(\mathrm{m} . \mathrm{K}), \mathrm{b})$ reinforced concrete, RC: $\lambda=1.58 \mathrm{~W} /(\mathrm{m} . \mathrm{K})$. Thickness of the concrete $t=200 \mathrm{~mm}$.

\section{Conclusion and recommendations}

In the present study we investigated the possibility of application of three types of wall cooling systems in existing buildings. The conclusions that may be drawn from this study are:

- It is recommended to install wall cooling system "a" with the pipes attached to the outer side of the wall only in special cases when installation on the inner surface should be avoided. It is preferable to combine this wall system with a bearing structure made of thermally conductive material such as reinforced concrete.

- The cooling output is greatest for wall system "b", especially when combined with the bearing structure made of the thermally conductive reinforced concrete. The cooling losses are lowest for wall system "c" owing to the additional insulation between the pipes and the bearing structure.

- System "b" is preferable to system "a" in cases when intervention on the interior side is possible, because of its higher cooling output. System " $b$ " can be preferable to system "c" in cases when we want to retain as much floor area as possible. This is because of the lower thickness of system "b" and consequently its lower requirement on the floor area.

- On the other hand, when the requirements on retaining the floor are not a key issue, system "c" can be preferable to system " $b$ ". Although the thickness of system "c" is higher than that of system "b" and it takes on more floor area, its losses are lower and it responds to changes in water temperature much faster.

- Thickness of thermal insulation is especially important for the thermally activated wall systems "a" and " $b$ " combined with reinforced concrete. The first $50 \mathrm{~mm}$ of insulation are crucial. Spacing of pipes is especially important for the wall systems "b" and "c" with pipes located in the inner surface layer.

- When located on an internal wall with no thermal insulation on the outer side, the cooling losses are always reasonably low for wall system "c" whose pipes are thermally insulated from the bearing structure, regardless of the material of the bearing structure. The losses are also reasonably low for wall system "b" whose pipes are thermally coupled to the bearing structure in case that the bearing structure is made of thermally insulating material such as porous concrete.

- Thermal response $\tau_{95}$ is a valid indicator of thermal dynamics of radiant systems. However, using thermal response as a single indicator of the thermal dynamics may be misleading.

- It is expected that the difference in performance of wall systems "b" and "c" will be best visible during their operation under dynamically changing boundary conditions. Future investigations should therefore involve additional dynamic simulations.

This work was supported by the Slovak Research and Development Agency under the Contract No. DS-2016-0030 and under the Contract No. APVV-16-0126, by the Ministry of Education, Science, Research and Sport of the Slovak Republic under VEGA Grant 1/0807/17, and by the Brno University of Technology Project No. FAST-J-19-5976 "Optimization of thermally activated structures".

\section{References}

1. C. Pout, E.R. Hitchin. Future environmental impacts of room air-conditioners in Europe. Build Res Inf 37 (2009).

2. S. Pezzutto, M. De Felice, R. Fazeli, L. Kranzl, S. Zambotti. Status Quo of the Air-Conditioning Market in Europe: Assessment of the Building Stock. Energies 10 (2017).

3. U. Akbulut, O. Kincay, Z. Utlu. Analysis of a wall cooling system using a heat pump. Renew Energ 85 (2016).

4. A.A. Márquez, J.M.C. López, F.F. Hernández, F.D. Muñoz, A.C. Andrés. A comparison of heating terminal units: Fan-coil versus radiant floor, and the combination of both. Energy Build 138 (2017).

5. J. Babiak, B.W. Olesen, D. Petráš. Low temperature heating and high temperature cooling. Rehva Guidebook No 7. $3^{\text {rd }}$ revised ed. Brussels, Belgium: Rehva (2013).

6. N. Harmati, R.J. Folić, Z.F. Magyar, J.J. Dražić, N.L. Kurtović-Folić. Building envelope influence on the annual energy performance in office buildings. Therm Sci 20 (2016).

7. R. Tomasi, M. Krajčík, A. Simone, B.W. Olesen. Experimental evaluation of air distribution in mechanically ventilated residential rooms: Thermal comfort and ventilation effectiveness. Energy Build 60 (2013).

8. J. Le Dréau, P. Heiselberg. Sensitivity analysis of the thermal performance of radiant and convective terminals for cooling buildings. Energy Build 82 (2014).

9. EN ISO 11855-2:2012. Building environment design - Design, dimensioning, installation and control of embedded radiant heating and cooling systems - Part 2: Determination of the design heating and cooling capacity. 
10. M. Krzaczek, Z. Kowalczuk. Thermal Barrier as a technique of indirect heating and cooling for residential buildings. Energy Build 43 (2011).

11. M. Šimko, M. Krajčík, O. Šikula, P. Šimko, D. Kalús Insulation panels for active control of heat transfer in walls operated as space heating or as a thermal barrier: Numerical simulations and experiments. Energy Build 158 (2018).

12. J. Xie, Q. Zhu, X. Xu. An active pipe-embedded building envelope for utilizing low-grade energy sources. J Cent South Univ 19 (2012).

13. O. Šikula. Software CalA User Manual (In Czech). Brno, Czech Republic: Tribun (2011).

14. J. Plasek, O. Šikula. Transient numerical simulation of linear thermal transmittance in software CalA. Adv Mater Res 1041 (2014).

15. EN ISO 6946:2017. Building components and building elements - Thermal resistance and thermal transmittance - Calculation methods.

16. S.V. Patankar. Numerical Heat Transfer and Fluid Flow. New York, USA: Hemisphere Publishing Corporation, Tailor \& Francis Group (1980).

17. ASHRAE. ASHRAE Handbook - Fundamentals. Atlanta, GA, USA: American Society of Heating, Refrigerating, and Air Conditioning Engineers (2017).

18. EN 15251:2007. Indoor environmental input parameters for design and assessment of energy performance of buildings addressing indoor air quality, thermal environment, lighting and acoustics.

19. R.W. Bliss jr. Atmospheric radiation near the surface of the ground: A summary for engineers. Sol Energy 5 (1961).

20. D.S. Parker, J.E.R. McIlvaine, S.F. Barkaszi, D.J. Beal, M.T. Anello. Laboratory testing of the reflectance properties of roofing material. Report FSEC-CR670-00. Florida, USA: Florida Solar Energy Center (2000).

21. J. Chyský, K. Hemzal. Větrání a klimatizace [Ventilation and air conditioning]. Prague, Czech Republic: Česká matice technická (1993).

22. STN 73 0548:1985. Výpočet tepelnej zát’ǎe klimatizovaných priestorov [Calculation of thermal load of air-conditioned spaces].

23. B. Ning, S. Schiavon, F. Bauman. A novel classification scheme for design and control of radiant system based on thermal response time. Energy Build 137 (2017). 